\title{
The toxicity of metal mixtures to the estuarine mysid Neomysis integer (Crustacea: Mysidacea) under changing salinity
}

\author{
Tim Verslycke ${ }^{\mathrm{a}, *}$, Marnix Vangheluwe ${ }^{\mathrm{b}}$, Dagobert Heijerick ${ }^{\mathrm{b}}$, Karel De \\ Schamphelaere ${ }^{\mathrm{a}}$, Patrick Van Sprang ${ }^{\mathrm{b}}$, Colin R. Janssen ${ }^{\mathrm{a}}$ \\ ${ }^{a}$ Laboratory of Environmental Toxicology and Aquatic Ecology, Ghent University, J. Plateaustraat 22, B-9000 Ghent, Belgium \\ ${ }^{\mathrm{b}}$ EURAS, Rijvisschestraat 118, B-9052 Zwijnaarde, Belgium
}

Received 29 August 2002; received in revised form 17 February 2003; accepted 28 February 2003

\begin{abstract}
Water quality criteria are mainly based on data obtained in toxicity tests with single toxicants. Several authors have demonstrated that this approach may be inadequate as the joint action of the chemicals is not taken into account. In this study, the combined effects of six metals on the European estuarine mysid Neomysis integer (Leach, 1814) were examined. Acute 96-h toxicity tests were performed with mercury, copper, cadmium, nickel, zinc and lead, and this as single compounds and as a mixture of all six. The concentrations of the individual metals of the equitoxic mixtures were calculated using the concentration-addition model. The 96-h LC50's for the single metals, at a salinity of 5\%, ranged from 6.9 to $1140 \mu \mathrm{g} / \mathrm{l}$, with the following toxicity ranking: $\mathrm{Hg}>\mathrm{Cd}>\mathrm{Cu}>\mathrm{Zn}>\mathrm{Ni}>\mathrm{Pb}$. Increasing the salinity from 5 to $25 \%$ resulted in lower toxicity and lower concentrations of the free ion (as derived from speciation calculations) for all metals. This salinity effect was strongest for cadmium and lead and could be attributed to complexation with chloride ions. The toxicity of nickel, copper and zinc was affected to a smaller extent by salinity. The 96-h LC50 for mercury was the same for both salinities. In order to evaluate the influence of changing salinity conditions on the acute toxicity of metal mixtures, tests were performed at different salinities $(5,10,15$ and $25 \%$ ). The $96-\mathrm{h}$ LC50 value $(1.49$ T.U.) of the metal mixture, at a salinity of $5 \%$, was clearly lower than the expected value (6 T.U.) based on the nonadditive hypothesis, thus confirming the additive effect of these metals in the marine/estuarine environment. Changing salinity had a profound effect on the toxicity of the mixture. The toxicity clearly decreased with increasing salinity until $15 \%$. Higher salinities $(25 \%$ ) had no further influence on the $96-\mathrm{h}$ LC50 of the mixture which is situated at a value between 4.4 and 4.6. Finally, the relative sensitivity to the selected metals was compared with the relative sensitivity of the commonly used mysid Americamysis ( = Mysidopsis) bahia.
\end{abstract}

(C) 2003 Elsevier Science B.V. All rights reserved.

Keywords: Combined effects; Metal toxicity; Mysid; Neomysis integer; Salinity; Speciation

\footnotetext{
* Corresponding author. Tel.: +32-9-264-3707; fax: +32-9-264-3766.

E-mail address: tim.verslycke@ugent.be (T. Verslycke).
} 


\section{Introduction}

Although aquatic organisms are usually exposed to a broad spectrum of toxicants in the environment, water quality criteria are generally derived for single compounds only, neglecting possible joint effects as synergism, antagonism and additivity. Attempts to model the joint action of chemicals have already been made for the freshwater environment (Altenburger et al., 1990; Drescher and Boedeker, 1995; Spehar and Fiandt, 1986). The toxicity of a mixture of chemicals with a similar mode of action can be predicted by the concentration-addition model as proposed by Anderson and Weber (1975). Different studies indicate additive effects of metals and organic compounds when occurring in a mixture (Altenburger et al., 1996; Sharma et al., 1999; Warne and Hawker, 1995). For Daphnia magna for example, Enserink et al. (1991) found that a mixture of metals present in a concentration well below their individual chronic values can still elucidate chronic effects on growth and reproduction. For the marine environment, however, information on this subject is limited.

This study examines the applicability of the concentration-addition model for assessing metal mixture toxicity in the marine/estuarine environment using the estuarine mysid Neomysis integer (Leach, 1814) and evaluates the effects of changing salinity conditions on the acute toxicity of metal mixtures. The choice of $N$. integer, a brackish water species indigenous to the European coastal waters, instead of the commonly used mysid Americamysis (= Mysidopsis) bahia (US-EPA, 1987) allows a more complete and realistic assessment of pollutant effects in European estuarine environments (Emson and Crane, 1994; Lussier et al., 1988; Roast et al., 1999; Wildgust and Jones, 1998). To explore the possible use of $N$. integer as an alternative to $A$. bahia, the sensitivity of these species were compared.

\section{Biology, distribution and life history}

$N$. integer, belonging to the genus Neomysis czerniavski, is one of the most common mysids inhabiting estuaries along the European coastlines. It is a hyperbenthic, euryhaline and eurythermic species, typically occurring in high numbers in estuarine and brackish water bodies (Tattersall and Tattersall, 1951). N. integer also inhabits closed oligohaline and freshwater bodies that were previously connected with the sea (Bremer and Vijverberg, 1982).

$N$. integer is an omnivorous species. As a predator on zooplankton it can structure zooplankton populations and as a detritivore it can also, to a certain extent, affect the detrital food chain (Mees et al., 1994). Due to its abundance, $N$. integer forms a major component in the marine food web. They are important prey for demersal and pelagic fish and larger epibenthic crustaceans (Mauchline, 1971; Mees et al., 1994; Tattersall and Tattersall, 1951).

Field observations on the hyperbenthic community of different European estuaries indicate that the $N$. integer dominates the community throughout the year with seasonal fluctuations. Peak abundances occur in spring and summer and lower abundances in winter (Mees et al., 1994, 1995).

\section{Materials and methods}

\subsection{Culturing procedures}

Initial $N$. integer populations were collected by handnet in the Galgenweel, a brackish water on the left bank of the river Scheldt near Antwerp, Belgium. Organisms were transferred to 601 plastic shallow holding tanks $(1.5 \times 0.4 \mathrm{~m})$ with a water depth of $10 \mathrm{~cm}$. Culture medium was filtered $(1.2 \mu \mathrm{m})$ natural seawater, diluted with aerated tap water to a salinity of $5 \%$. The laboratory culture was maintained under a 12-h light:12-h dark photoperiod. Holding tanks were aerated continuously and water quality was maintained using a gravel bottom filter and through renewal of $50 \%$ of the culture medium every week. Ammonia and ammonium concentrations were checked twice a week. Cultures were fed ad libitum twice daily with 24-48-h old Artemia nauplii to prevent adult mysids from cannibalizing their young. A feeding rate of 150 nauplii/mysid/day, as recommended for 
$N$. mercedis by Brandt et al. (1993), was applied. Hatching of the Artemia cysts was performed in 11 cylindro-conical vessels under vigorous aeration and continuous illumination at $25{ }^{\circ} \mathrm{C}$. Culture density was kept at 20 mysids/l. Due to their epibenthic behavior the number of mysids per unit bottom volume may be more limiting than the number of mysids per unit water volume (Brandt et al., 1993).

\subsection{Collection of test organisms}

Although $N$. integer has been occasionally used as a test organism in toxicity tests (Emson and Crane, 1994; Laughlin and Lindén, 1983; Roast et al., 1999, 2000, 2001; Von Oertzen et al., 1988) so far no attempt has been made to develop culturing procedures and consequently organisms of mixed age (adults) have been used in previous studies. Sensitivity, however, can differ from one life stage to another and the use of juveniles not only increases sensitivity, but also allows standardization. Juveniles were separated from adult females by using a netted brood chamber (Breteler et al., 1982). Depending on the age of the female, brood size ranged from 7 to 17 juveniles. To ensure sufficient test juveniles, we used-as a rule of thumb-one gravid female for each required juvenile. After a 24-h period, newly released neonates were collected. This procedure was followed during a 5-day period until a sufficient number of juveniles were available to perform the toxicity tests.

\subsection{Toxicity test procedures}

\subsubsection{Acute toxicity of six metals}

Acute 96-h toxicity tests were carried out with mercury $\left(\mathrm{HgCl}_{2}\right)$, cadmium $\left(\mathrm{CdCl}_{2} \cdot 2.5 \mathrm{H}_{2} \mathrm{O}\right)$, copper $\left(\mathrm{CuCl}_{2}\right)$, zinc $\left(\mathrm{ZnCl}_{2}\right)$, nickel $\left(\mathrm{NiCl}_{2}\right)$ and lead $\left(\mathrm{Pb}\left(\mathrm{NO}_{3}\right)_{2}\right)$ in order to determine the LC50 of these metals. All metals were of analytical grade and were purchased from UCB (Belgium). Toxicity tests were conducted in similar conditions as those recommended for the acute $A$. bahia toxicity test (US-EPA, 1987) at two different salinities, 5 and $25 \%$. Ten juveniles between 1 - and 5-days old were randomly distributed to $200-\mathrm{ml}$ test vessels containing $180 \mathrm{ml}$ of the toxicant solution. Two replicates for each of the five toxicant concentrations and a control were tested. For each metal two definitive tests were performed. Toxicant stock solutions were prepared in deionized water at 100 times the desired concentration. Actual test concentrations were determined by atomic absorption spectrometry (flame-, graphite furnace-, or cold vapor AAS depending on the metal) and were within $10 \%$ of the nominal values. The required serial dilutions were made from the stock solutions with filtered $(1.2 \mu \mathrm{m})$ natural seawater and adjusted to the desired salinity with deionized water. Test organisms were fed daily at a rate of 150 Artemia nauplii/mysid/day. All tests were conducted at $20 \pm 1{ }^{\circ} \mathrm{C}$ in a temperature controlled room and a 12-h light:12-h dark photoperiod was maintained. Test solutions were renewed daily and the number of surviving mysids was noted. Dead organisms and debris were removed. Acute effects are reported as 96-h LC50 values (expressed as microgram per liter of the metal) and were calculated by the moving average method (Stephan, 1977). Metal speciation calculations were performed using the geochemical speciation model visual MINTEQ (download from http://www.amov.ce.kth.se/people/gustafjp/vminteq.htm) on the base of an average seawater composition as derived from Sadiq (1992).

\subsubsection{Mixture toxicity experiments}

The joint effect of the six metals was evaluated using the concentration-addition model. In this approach the concentration of each single toxicant is expressed as a fraction of its LC50 (toxic unit, T.U.). Based on the 96-h LC50 values of the single metals at a salinity of $5 \%$, mixtures of these metals were prepared in equitoxic concentrations, i.e. each metal is present in the same fraction of its effective concentration (96-h LC50). The expected toxicity (toxic strength) of the mixtures (based on the non-additive hypothesis) was expressed as toxic units (T.U.), i.e. the sum of the ratios of actual metal concentration to their effective concentrations (LC50):

Expected toxicity (T.U.) $=\sum \mathrm{Cm}_{\mathrm{i}}, \mathrm{a} / \mathrm{Cm}_{\mathrm{i}}, \mathrm{e}$ 
where $\mathrm{Cm}_{\mathrm{i}}, \mathrm{a}$ : actual metal concentration; $\mathrm{Cm}_{\mathrm{i}}$, $\mathrm{e}$ : effective metal concentration (96-h LC50).

In case of complete concentration addition the $50 \%$ response of a mixture of chemicals is obtained when the sum of T.U. of all constituents equals unity. More than addition gives $\Sigma$ T.U. $<1$ and less than addition $\Sigma$ T.U. $>1$.

Nine equitoxic mixtures of the six metals were tested $(0.5,1,1.5,2,2.5,3,5,7$ and 9 T.U.). Note that these sums function as a unit of additive toxicity, except that values greater than 1 are not symmetrical with values less than 1 (Spehar and Fiandt, 1986). For example, in our tests a value of 6 would indicate that there would be no interaction because six toxicants made up the mixture; however, values of 0.5 and 3.0 would be equally more than additive and less than additive, respectively, since they are midway between 0 and 1 , and 0 and 6 .

\subsubsection{Effect of salinity on the acute mixture toxicity}

The acute toxicity of the nine equitoxic mixtures was determined at different salinities: 5, 10, 15 and $25 \%$. Test organisms were taken from the culture (culturing salinity is $5 \%$ ) and acclimated to the specific salinity of the test conditions, 2 days prior to the toxicity test. This acclimation period was considered to be sufficient, since a previous study has demonstrated that mysids are extremely efficient osmoregulators, attaining osmotic balance within 2-h of exposure to a change in salinity (Moffat, 1996).

\section{Results}

\subsection{Acute toxicity of six metals}

Control survival in all 96-h tests ranged from 90 to $100 \%$. Acute toxicity data for $N$. integer and $A$. bahia, the latter taken from literature data, are summarized in Table 1. At a salinity of $5 \%$, mercury was the most toxic to $N$. integer juveniles $(96-\mathrm{h} \mathrm{LC50}=6.9 \mu \mathrm{g} / \mathrm{l})$ and lead $(96-\mathrm{h} \mathrm{LC50}=1140$ $\mu \mathrm{g} / \mathrm{l})$ proved to be the least toxic among the metals tested. Based on these 96-h LC50 values, the following decreasing toxicity order was obtained:
Table 1

Comparison of the 96-h LC50 values of six metals for $N$. integer and A. bahia. Free ion concentrations and activities of the six metals were calculated for two tested salinities $(5 \%$ and $25 \%$ )

\begin{tabular}{|c|c|c|c|}
\hline \multirow[t]{2}{*}{ Salinity } & \multicolumn{2}{|l|}{$N$. integer } & \multirow{2}{*}{$\begin{array}{l}\text { A. bahia } \\
30 \%\end{array}$} \\
\hline & $5 \%$ & $25 \%$ & \\
\hline $\begin{array}{l}\text { Mercury (Hg) } \\
{\left[\mathrm{Hg}^{2+}\right]^{\mathrm{d}}} \\
\left(\mathrm{Hg}^{2+}\right)^{\mathrm{e}}\end{array}$ & $\begin{array}{l}6.9^{\mathrm{a}} \\
(3.1-10.7) \\
<1 \% \\
1.68 \times 10^{-20}\end{array}$ & $\begin{array}{l}7.0 \\
(3.4-11.1) \\
<1 \% \\
1.00 \times 10^{-22}\end{array}$ & $\begin{array}{l}3.5^{\mathrm{b}, \mathrm{c}} \\
(2.7-4.8)\end{array}$ \\
\hline $\begin{array}{l}\text { Cadmium }(\mathrm{Cd}) \\
{\left[\mathrm{Cd}^{2+}\right]} \\
\left(\mathrm{Cd}^{2+}\right)\end{array}$ & $\begin{array}{l}45 \\
(41-49) \\
19.7 \% \\
2.87 \times 10^{-8}\end{array}$ & $\begin{array}{l}318 \\
(262-416) \\
3.4 \% \\
2.86 \times 10^{-8}\end{array}$ & $\begin{array}{l}110^{\mathrm{b}, \mathrm{f}} \\
(102-118)\end{array}$ \\
\hline $\begin{array}{l}\text { Copper }(\mathrm{Cu}) \\
{\left[\mathrm{Cu}^{2+}\right]} \\
\left(\mathrm{Cu}^{2+}\right)\end{array}$ & $\begin{array}{l}46 \\
(41-51) \\
17.3 \% \\
4.56 \times 10^{-8}\end{array}$ & $\begin{array}{l}68 \\
(57-83) \\
20.5 \% \\
6.46 \times 10^{-8}\end{array}$ & $\begin{array}{l}181^{\mathrm{b}} \\
(146-250)\end{array}$ \\
\hline $\begin{array}{l}\operatorname{Zinc}(\mathrm{Zn}) \\
{\left[\mathrm{Zn}^{2+}\right]} \\
\left(\mathrm{Zn}^{2+}\right)\end{array}$ & $\begin{array}{l}540 \\
(318-762) \\
74.0 \% \\
2.22 \times 10^{-6}\end{array}$ & $\begin{array}{l}1037 \\
(841-1291) \\
49.2 \% \\
2.30 \times 10^{-6}\end{array}$ & $\begin{array}{l}499^{\mathrm{b}} \\
(350-600)\end{array}$ \\
\hline $\begin{array}{l}\text { Nickel (Ni) } \\
{\left[\mathrm{Ni}^{2+}\right]} \\
\left(\mathrm{Ni}^{2+}\right)\end{array}$ & $\begin{array}{l}765 \\
(435-1095) \\
82.8 \% \\
3.92 \times 10^{-6}\end{array}$ & $\begin{array}{l}1042 \\
(870-1263) \\
65.5 \% \\
3.43 \times 10^{-6}\end{array}$ & $\begin{array}{l}508^{\mathrm{b}} \\
(387-635)\end{array}$ \\
\hline $\begin{array}{l}\text { Lead }(\mathrm{Pb}) \\
{\left[\mathrm{Pb}^{2+}\right]} \\
\left(\mathrm{Pb}^{2+}\right)\end{array}$ & $\begin{array}{l}1140 \\
(840-1440) \\
17.9 \% \\
3.58 \times 10^{-7}\end{array}$ & $\begin{array}{l}4274 \\
(3540-5710) \\
7.3 \% \\
4.43 \times 10^{-7}\end{array}$ & $\begin{array}{l}3130^{\mathrm{b}} \\
(2350-\infty)\end{array}$ \\
\hline
\end{tabular}

a Tabulated 96-h LC50 values are expressed in microgram per liter with $95 \%$ confidence limits in parentheses.

${ }^{b}$ Lussier et al. (1985).

c Gentile et al. (1983).

d $\%$ metal as the free ion.

${ }^{\mathrm{e}}$ Free metal ion activity.

${ }^{\mathrm{f}}$ Gentile et al. (1982).

$\mathrm{Hg}>\mathrm{Cd}>\mathrm{Cu}>\mathrm{Zn}>\mathrm{Ni}>\mathrm{Pb}$. Increasing the salinity from 5 to $25 \%$ slightly alters this sequence. Copper replaces cadmium and the following ranking is obtained: $\mathrm{Hg}>\mathrm{Cu}>\mathrm{Cd}>\mathrm{Zn}>\mathrm{Ni}>$ $\mathrm{Pb}$. When expressing toxicity on a micromole per liter scale, the order is also slightly altered with copper replacing cadmium at $5 \%$ and nickel replacing zinc at $25 \%$. 
The coefficient of variation (S.D. $\times 100 /$ mean) of the performed tests ranged from 2.8 to $27.5 \%$, indicating good repeatability.

\subsection{Metal mixture toxicity}

The concentration-response curve for the equitoxic mixtures of six metals tested at different salinities is presented in Fig. 1. The nominal concentration of each metal in the different mixtures is presented in Table 2. In absence of additive effects, the 96-h LC50 of the mixture is expected to be found in a mixture where each metal is present in a concentration equal to its individual 96-h LC50. For example, each metal contributes 1 T.U. to the toxic strength of the mixture resulting in an expected toxic strength of 6 T.U. The results, however, show a 50\% mortality in a mixture with a toxic strength of 1.49 T.U. where each metal is present at $1 / 4$ of its individual LC50.

As shown in Fig. 1, changing the salinity has a profound effect on the toxicity of the mixture. The toxicity clearly decreases with increasing salinity until $15 \%$. Higher salinities had no further influence on the 96-h LC50 of the mixture which is situated at a value between 4.4 and 4.6 T.U. (Table $3)$.

\section{Discussion}

Correlation analysis revealed a positive and significant correlation $\left(r^{2}=0.90 ; P=0.0037\right)$ between the mean 96-h LC50 values, obtained at a salinity of $25 \%$, for $N$. integer and those of $A$. bahia (at 30\%). The mean 96-h LC50 values (at $25 \%$ ) for mercury $(7 \mu \mathrm{g} / 1)$, cadmium $(318 \mu \mathrm{g} / \mathrm{l})$, zinc $(1037 \mu \mathrm{g} / \mathrm{l})$, nickel $(1042 \mu \mathrm{g} / \mathrm{l})$ and lead (4274 $\mu \mathrm{g} / \mathrm{l})$ for $N$. integer are higher than the reported literature values for $A$. bahia as shown in Table 1. The mean 96-h LC50 value for copper $(68 \mu \mathrm{g} / \mathrm{l})$ is markedly lower than the value obtained by Lussier et al. (1985) for the marine mysid A. bahia $(181 \mu \mathrm{g} /$ 1). The 96-h LC50 obtained for cadmium $(318 \mu \mathrm{g} / \mathrm{l})$ is higher than the value $(151 \mu \mathrm{g} / \mathrm{l})$ reported by Roast et al. (2001) at a salinity of 30\%. Emson and Crane (1994) found an extremely high sensitivity for $N$. integer to cadmium and found a 96-h LC50 between 1 and $3 \mu \mathrm{g} / \mathrm{l}$. These values do not corroborate our findings.

Decreasing the salinity to $5 \%$ generally resulted in lower 96-h LC50 values of the tested metals for $N$. integer. This salinity effect becomes clearer, when the results of the combined toxicity experiments are considered. At a salinity of 5\%,50\% mortality was observed in a mixture with a toxic strength of 1.49 T.U., i.e. each metal is present at $1 / 4$ of its individual LC50, suggesting a nearly strictly additive joint action. This result is compar-

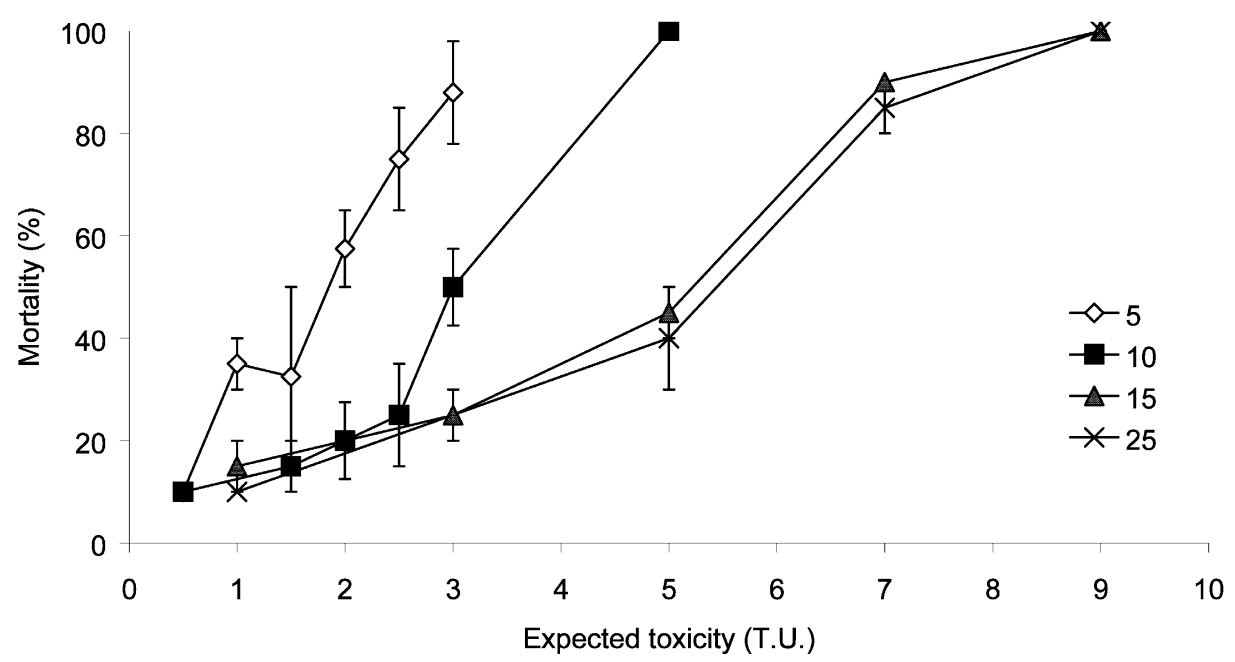

Fig. 1. The concentration-response curve of $N$. integer for a mixture of six metals at different salinities $(5,10,15$ and $25 \%$ ). 
Table 2

Nominal concentrations $(\mu \mathrm{g} / \mathrm{l})$ of the six metals in an acute toxicity test with $N$. integer. Test organisms were exposed to dilutions of equitoxic mixtures

\begin{tabular}{|c|c|c|c|c|c|c|c|c|c|}
\hline & \multicolumn{9}{|c|}{ Toxic unit (T.U.) } \\
\hline & 0.5 & 1 & 1.5 & 2 & 2.5 & 3 & 5 & 7 & 9 \\
\hline $\mathrm{Hg}$ & 0.6 & 1.1 & 1.7 & 2.3 & 3.0 & 3.5 & 5.8 & 8.1 & 10.4 \\
\hline $\mathrm{Cd}$ & 3.8 & 7.5 & 11.3 & 15 & 18.8 & 22.5 & 37.5 & 52.5 & 67.5 \\
\hline $\mathrm{Cu}$ & 3.8 & 7.6 & 11.5 & 15.3 & 19.2 & 23 & 38.3 & 53.7 & 69 \\
\hline $\mathrm{Zn}$ & 45 & 90 & 135 & 180 & 225 & 270 & 450 & 630 & 810 \\
\hline $\mathrm{Ni}$ & 64 & 128 & 191 & 225 & 319 & 383 & 638 & 893 & 1148 \\
\hline $\mathrm{Pb}$ & 95 & 190 & 285 & 380 & 475 & 570 & 950 & 1330 & 1710 \\
\hline
\end{tabular}

Table 3

Toxicity (96-h LC50) for an equitoxic mixture of six metals to $N$. integer at four different salinities

\begin{tabular}{ll}
\hline Salinity & $96-\mathrm{h} \mathrm{LC50}$ \\
\hline $5 \%$ & $1.49^{\mathrm{a}}$ \\
& $(1.19-1.81)$ \\
$10 \%$ o & 3.07 \\
& $(2.64-4.20)$ \\
& 4.61 \\
& $(3.87-5.41)$ \\
& 4.37 \\
$20 \%$ & $(3.51-5.29)$ \\
\hline
\end{tabular}

a Tabulated 96-h LC50 values are expressed in toxic units with $95 \%$ confidence limits in parentheses.

able to the value found by Enserink et al. (1991) of $1.8(0.89-3.1)$ T.U. at which a $50 \%$ mortality was observed in D. magna juveniles exposed to a mixture of eight metals. Similarly, Spehar and Fiandt found near complete addition (1.47 T.U.) in Ceriodaphnia dubia exposed to a mixture of six metals. Increasing the salinity in this study shifted the $96-\mathrm{h} \mathrm{LC50}$ of the mixture from 1.49 T.U. to a value which is situated between 4.4 and 4.6 T.U.

The individual contribution of each metal to the toxic strength of the mixture at a salinity of $25 \%$ can be calculated by dividing the actual metal concentrations (i.e. the individual metal concentrations in the 4.37 T.U. mixture) with the 96-h LC50 values obtained for each individual metal at the same salinity (Table 4). Keeping in mind that we initially departed from an equitoxic mixture at a salinity of $5 \%$, it can be clearly shown that at a salinity of $25 \%$ the contribution of each metal is different (i.e. deviates from the expected contribution of 1 T.U.), indicating specific salinity effects for the investigated metals. Cadmium and lead which contribute 0.11 and 0.19 T.U. to the overall mixture toxicity are the most influenced by increasing salinity. The toxicity of mercury on the other hand shows little change (0.72 T.U.). Zinc, nickel and copper contribute in equal fractions to the toxicity of the mixture.

One possible mechanism that can explain the observed phenomenon is complexation of the metals with chloride ions (Wright, 1995). The most commonly accepted explanation for the increased toxicity of metals at low salinity is that the free metal ion - the most bioavailable form is most abundant at low salinity because of reduced formation of chloro-complexes. Cadmium and lead speciation (in cases where total dissolved $\mathrm{Pb}$ remains the same) and bioaccumulation are primarily influenced by inorganic ligands as $\mathrm{Cl}^{-}$. Both inorganic- and organic ligand concentrations determine the speciation of copper (Sadiq, 1992).

For cadmium, salinity is the overriding factor which can alter free $\mathrm{Cd}$ ion activity and hence bioavailability and toxicity of cadmium in marine systems (Sadiq, 1992; Sunda et al., 1978). Blust et al. (1992) investigated the effect of salinity on cadmium uptake with the brine shrimp Artemia fransiscana and found a decrease in the cadmium uptake with increasing salinity. De Lisle and Roberts (1988, 1994) and Roast et al. (2001) also earmarked $\mathrm{Cd}^{2+}$ as the primary toxic species for $A$. bahia and $N$. integer. When cadmium speciation in our study was modeled, free ion percen- 
Table 4

Calculated contribution (A/B) of the six tested metals, based on the concentration in the mixture (A) and the individual 96-h LC50 (B), to the toxicity of the mixture to $N$. integer at a salinity of $25 \%$

\begin{tabular}{|c|c|c|c|}
\hline Metal & Concentration in mixture $(\mu \mathrm{g} / \mathrm{l})(\mathrm{A})^{\mathrm{a}}$ & Individual 96-h LC50 ${ }_{(25 \%)}(\mu \mathrm{g} / 1)(\mathrm{B})$ & Contribution (T.U.) (A/B) \\
\hline $\mathrm{Hg}$ & 5.1 & 7.0 & 0.72 \\
\hline $\mathrm{Cd}$ & 32 & 318 & 0.11 \\
\hline $\mathrm{Cu}$ & 34 & 68 & 0.49 \\
\hline $\mathrm{Zn}$ & 393 & 1037 & 0.38 \\
\hline $\mathrm{Ni}$ & 557 & 1042 & 0.53 \\
\hline $\mathrm{Pb}$ & 830 & 4276 & 0.19 \\
\hline
\end{tabular}

a Actual concentrations of the individual metals in a 4.37 T.U. mixture which caused $50 \%$ mortality at a salinity of $25 \%$.

tages $\left(\mathrm{Cd}^{2+}\right)$ were calculated to be 19.7 and 3.4 , at 5 and $25 \%$, respectively (Table 1 ). These values are in agreement with earlier published speciation estimates (De Lisle and Roberts, 1994; Roast et al., 2001) and demonstrate that the toxicity difference observed at the two salinities are caused by differences in the free $\mathrm{Cd}$ ion.

The reduced contribution of lead to the toxicity of the mixture is probably due to precipitation. At the normal $\mathrm{pH}$ of seawater, most of the total amount of lead is precipitated as lead (II) chloride and about $10 \%$ is an active ion form (Byrne and Miller, 1984). Free ion percentages in our study were $17.9 \%$ (at $5 \%$ ) and $7.3 \%$ (at $25 \%$ ) for $\mathrm{Pb}^{2+}$, which is in accordance with the observed lower toxicity at the highest salinity.

The 96-h LC50 of mercury for $N$. integer is the same for both tested salinities (5 and 25\%), respectively 6.9 and $7.0 \mu \mathrm{g} / \mathrm{l}$. Speciation calculations for $\mathrm{Hg}$ resulted in similar very low free ion percentages $\left(<1 \% \mathrm{Hg}^{2+}\right)$ at both salinities. Consequently, it can be concluded that salinity has a minor effect on the speciation and toxicity of mercury species to $N$. integer.

The toxicity of nickel, copper and zinc was affected to a smaller extent by salinity. According to Kushner (1993) nickel ions are not complexed by $\mathrm{Cl}^{-}$, even in seawater and the concentrations of $\mathrm{Cl}^{-}$that occur in seawater do not affect the toxicity of this metal. This is in contradiction with Nriagu (1980) who stated that considerable portions of the nickel ions were reported to exist in seawater as complexes with chloride and sulphate ions, leading to the depletion of free nickel ions. Our results support the latter statement if the free nickel ion can be considered as the most toxic form. With regard to copper one has to be cautious. Copper probably forms stronger complexes with organic ligands than any other trace metal at comparable concentrations. The distribution of $\mathrm{Cu}$ between ionic and complexed forms (both organic and inorganic) in seawater is complicated and many investigators have speculated on inorganic $\mathrm{Cu}$ speciation (Sadiq, 1992). It may, however, be generalized that $\mathrm{Cu}-\mathrm{Cl}$ complexes will increase as the salinity increases and this will decrease bioaccumulation and toxicity. Cupric $\left(\mathrm{Cu}^{2+}\right)$ is the most biotoxic form and varied little in our study according to the speciation calculations; $17.3 \%$ (at 5\%o and 20.5\% (at 25\% ). The observed slight reduction in copper toxicity at higher salinities is therefore difficult to link to inorganic complexation behavior.

Finally, the lower zinc toxicity at higher salinities correlated well with the observed decrease in the free $\mathrm{Zn}$ ion; $74.0 \%$ (at 5\%) and 49.2 (at 25\%).

Since our speciation calculations did not account for the presence of organic carbon in the test medium, we were not able to account for sorption of the tested metals to these organic colloids. It has been demonstrated that these mechanisms affect metal speciation, primarily by reducing the dissolved concentrations, and ultimately influencing the bioavailability and toxicity of metals (Cantwell and Burgess, 2001). Unfortunately, data on modelling these mechanisms in seawater are very scarce and future research should focus on the quantitative understanding of these processes, which should allow a more fundamental understanding of the influence of salinity and organic content on 
the speciation and toxicity of individual metals and metal mixtures in marine environments.

\section{Conclusions}

In this study, the combined effects of six metals on $N$. integer were examined at different salinities. At a salinity of $5 \%, 50 \%$ mortality was observed in a mixture with a toxic strength of 1.49 T.U. suggesting a nearly strictly additive joint action. Higher salinities resulted in lower toxicity. This salinity effect could be partly attributed to complexation of the metals with chloride ions, i.e. lower free metal ion concentrations at a salinity of $25 \%$ resulted in lower toxicity. This effect was stronger for $\mathrm{Cd}$ and $\mathrm{Pb}$ than for $\mathrm{Zn}, \mathrm{Cu}$ and $\mathrm{Ni}$. $\mathrm{Pb}$ toxicity was unaffected by salinity.

\section{References}

Altenburger, R., Bödeker, W., Faust, M., Grimme, L.H., 1990. Evaluation of the isobologram method for the assessment of mixtures of chemicals. Ecotoxicol. Environ. Saf. 20, $98-$ 114.

Altenburger, R., Bödeker, W., Faust, M., Grimme, L.H., 1996. Regulations for combined effects of pollutants: consequences from risk assessment in aquatic toxicology. Food Chem. Toxicol. 34, 1155-1157.

Anderson, P.D., Weber, L.J., 1975. The toxicity to aquatic populations of mixtures containing certain heavy metals. Proceedings of the International Conference on Heavy Metals in the Environment, October 27-31, Toronto, Ontario, Canada, pp. 933-954.

Blust, R., Kockelbergh, E., Baillieul, M., 1992. Effect of salinity on the uptake of cadmium by the brine shrimp Artemia franciscana. Mar. Ecol. Prog. Ser. 84, 245-254.

Brandt, O.M., Fujimura, R.W., Finlayson, B.J., 1993. Use of Neomysis mercedis (Crustacea: Mysidacea) for estuarine toxicity tests. T. Am. Fish. Soc. 122, 279-288.

Bremer, P., Vijverberg, J., 1982. Production, population biology and diet of Neomysis integer (Leach) in a shallow Frisian lake (The Netherlands). Hydrobiologia 93, 41-51.

Breteler, R.J., Williams, W., Buhl, R.L., 1982. Measurement of chronic toxicity using the opossum shrimp Mysidopsis bahia. Hydrobiologia 93, 189-194.

Byrne, R.H., Miller, W.L., 1984. Medium composition of dependence of lead (II) complexation by chloride ions. Am. J. Sci. 284, 79-94.

Cantwell, M.G., Burgess, R.M., 2001. Metal-colloid partitioning in artificial interstitial waters of marine sediments: influences of salinity, $\mathrm{pH}$, and colloidal organic carbon concentration. Environ. Toxicol. Chem. 20, 2420-2427.

De Lisle, P.F., Roberts, M.H., Jr., 1988. The effect of salinity on cadmium toxicity to the estuarine mysid Mysidopsis bahia: role of chemical speciation. Aquat. Toxicol. 12, 357370.

De Lisle, P.F., Roberts, M.H., Jr., 1994. The effect of salinity on cadmium toxicity in the estuarine mysid Mysidopsis bahia: roles of osmoregulation and calcium. Mar. Environ. Res. 37, 47-62.

Drescher, K., Boedeker, W., 1995. Assessment of the combined effects of substances: the relationship between concentration addition and independent action. Biometrics 51, 716-730.

Emson, S., Crane, M., 1994. A comparison of the toxicity of cadmium to the mysid shrimps Neomysis integer (Leach) and Mysidopsis bahia (Molenock). Water Res. 28, 17111713.

Enserink, E.L., Maas-Diepeveen, J.L., Van Leeuwen, C.J., 1991. Combined effects of metals: an ecotoxicological evaluation. Water Res. 25, 679-687.

Gentile, S.M., Gentile, J.H., Walker, J., Heltshe, J.F., 1982. Chronic effects of cadmium on two species of mysid shrimp: Mysidopsis bahia and Mysidopsis bigelowi. Hydrobiologia 93, 195-204.

Gentile, J.H., Gentile, S.M., Hoffman, G., Heltshe, J.F., Hairston, N., Jr., 1983. The effects of a chronic mercury exposure on survival, reproduction and population dynamics of Mysidopsis bahia. Environ. Toxicol. Chem. 2, 61-68.

Kushner, D.J., 1993. Effects of speciation of toxic metals on their biological activity. Water Pollut. Res. J. Can. 28, $111-$ 128.

Laughlin, R., Lindén, O., 1983. Oil pollution and Baltic mysids: acute and chronic effects of the water soluble fraction of light fuel oil on the mysid shrimp Neomysis integer. Mar. Ecol. Prog. Ser. 12, 29-41.

Lussier, S.M., Gentile, J.H., Walker, J., 1985. Acute and chronic effects of heavy metals and cyanide on Mysidopsis bahia (Crustacea: Mysidacea). Aquat. Toxicol. 7, 25-35.

Lussier, S.M., Kuhn, A., Chammas, M.J., Sewall, J., 1988. Techniques for the laboratory culture of Mysidopsis species (Crustacea: Mysidacea). Environ. Toxicol. Chem. 7, 969977.

Mauchline, J., 1971. The biology of Neomysis integer. J. Mar. Biol. Ass. UK 51, 347-354.

Mees, J., Abdulkerim, Z., Hamerlynck, O., 1994. Life history, growth and production of Neomysis integer in the Westerschelde estuary (SW Netherlands). Mar. Ecol.-Prog. Ser. 109, 43-57.

Mees, J., Fockedey, N., Hamerlynck, O., 1995. Comparative study of the hyperbenthos of three European estuaries. Hydrobiologia 311, 153-174.

Moffat, A.M., 1996. Ecophysiology of mysids (Crustacea: Pericarida) in the river Tamar estuary. Ph.D. Thesis. University of Plymouth, Plymouth, UK.

Nriagu, J.O., 1980. Nickel in the Environment. Wiley, New York. 
Roast, S.D., Thompson, R.S., Donkin, P., Widdows, J., Jones, B., 1999. Toxicity of the organophosphate pesticides chlorpyrifos and dimethoate to Neomysis integer (Crustacea, Mysidacea). Water Res. 33, 319-326.

Roast, S.D., Widdows, J., Jones, M.B., 2000. Disruption of swimming in the hyperbenthic mysid Neomysis integer (Peracarida: Mysidacea) by the organophosphate pesticide chlorpyrifos. Aquat. Toxicol. 47, 221-241.

Roast, S.D., Widdows, J., Jones, M.B., 2001. Effects of salinity and chemical speciation on cadmium accumulation and toxicity to two mysid species. Environ. Toxicol. Chem. 20, $1078-1084$

Sadiq, M., 1992. Toxic Metal Chemistry in Marine Environments. Dekker, New York.

Sharma, S.S., Schat, H., Vooijs, R., Van Heerwaarden, L.M., 1999. Combination toxicology of copper, zinc, and cadmium in binary mixtures: concentration-dependent antagonistic, nonadditive, and synergistic effects on root growth in Silene vulgaris. Environ. Toxicol. Chem. 18, 348-355.

Spehar, R.L., Fiandt, J.T., 1986. Acute and chronic effects of water quality criteria-based metal mixtures on three aquatic species. Environ. Toxicol. Chem. 5, 917-931.

Stephan, C.E., 1977. Methods for calculating an LC50. In: Mayer, F.I., Hamelink, J.L. (Eds.), Aquatic Toxicology and
Hazard Evaluation. American Society for Testing and Materials STP 634, pp. 65-84.

Sunda, W.G., Engel, D.W., Thuotte, R.M., 1978. Effect of chemical speciation on toxicity of cadmium to grass shrimp, Palaemonetes pugio: importance of free cadmium ion. Environ. Sci. Technol. 12, 409-413.

Tattersall, W.M., Tattersall, O.S., 1951. The British Mysidacea. The Ray Society, London.

US-EPA, 1987. Short-term methods for estimating chronic toxicity of effluents and receiving waters to marine and estuarine organisms. EPA 600/4-87-028. Cincinnati, OH.

Von Oertzen, J.-A., Wulf, D., Brügmann, L., 1988. Ecotoxicological effects of two mercury compounds on Neomysis integer (Leach) and Pomatoschistus microps (Kroyer). Kieler Milchw Forsch. 6, 414-423.

Warne, M.S.J., Hawker, D.W., 1995. The number of components in a mixture determines whether synergistic and antagonistic or additive toxicity predominate: the funnel hypothesis. Ecotoxicol. Environ. Saf. 31, 23-28.

Wildgust, M., Jones, M.B., 1998. Salinity change and the toxicity of the free cadmium ion $\left[\mathrm{Ca}_{(\mathrm{aq})}^{2+}\right]$ to Neomysis integer (Crustacea; Mysidacea). Aquat. Toxicol. 41, 187-192.

Wright, D.A., 1995. Trace metal and major ion interactions in aquatic organisms. Mar. Pollut. Bull. 31, 8-18. 